\title{
Assay of preS epitopes and preS1 antibody in hepatitis B virus carriers and immune persons
}

\author{
R. Deepen, K.-H. Heermann, A. Uy, R. Thomssen, and W. H. Gerlich \\ Hygiene Institut, Georg-August-Universität, Kreuzbergring 57, D-3400 Göttingen, \\ Federal Republic of Germany
}

\begin{abstract}
The diagnostical significance of the large hepatitis B surface protein with its preSl attachment site and of anti-preS antibodies are not yet well known. We investigated the epitope of the preS1 attachment site to see whether it is a marker of viremia and whether antibodies against it occur in convalescents and vaccinees. For comparison, sera were also tested for the presence and relative amount of a preS2 epitope. The epitopes were detected by binding to specific monoclonal antibodies (mAb MA18/7 for the preSl epitope and mAb Q19/10 for the preS2 epitope) at the solid phase of a sandwich enzyme-linked immunosorbent assay. Antibody against the preS1 epitope was detected by inhibition of binding to mAb MA18/7. This $\mathrm{mAb}$ inhibits attachment of preS1 antigen to hepatocytes and reacts with a subtypeindependent sequential epitope at the surface of hepatitis B virus between amino acid 29-36. This preS1 epitope occurs in most hepatitis B surface antigen (HBsAg) carriers, irrespective of viremia. Free preS2 epitope Q19/10 is present in samples with more than $8 \mu \mathrm{g} / \mathrm{ml}$ total HBsAg and it is masked in sera with less HBsAg. Antibodies which compete with mAb MA18/7 for its viral preS1 epitope occur in one third of HBsAg carriers who were negative for hepatitis B e antigen. It also occurs in one third of convalescents and in most good responders to plasma-derived vaccines.
\end{abstract}

\section{Introduction}

Hepatitis B virus surface antigen (HBsAg) is present on the envelope of hepatitis B virus (HBV) and in its noninfectious form on filamentous and spherical particles of 20-nm diameter. Viremic HBV carriers produce and secrete these three forms of 
particles to the blood, while non- or low-viremic carriers secrete only the $20-\mathrm{nm}$ spherical particles to the blood. HBsAg consists of three coterminal proteins which are encoded by region $\mathrm{S}$ of the HBV genome. The three proteins (large, middle and small) are generated by the alternate use of three translational start codons and by a common stop codon. The small HBs protein (SHBs) forms the spherical 20-nm particles. These particles contain, furthermore, small amounts of the middle (MHBs) and of the large HBs protein (LHBs). The filamentous HBsAg particles and the HBV envelope contain larger amounts of LHBs (Heermann et al. 1984). LHBs have in contrast to MHBs or SHBs a preS1 domain. It has been suggested that preS1 antigen is a marker for viremia (Theilmann et al. 1986), but other studies (Heermann et al. 1984; Hu et al. 1987; Budkowska et al. 1988) do not support this suggestion. In this report we studied the occurrence of preS1 antigen in various states of HBV infections. We used a monoclonal antibody (mAb) MA18/7 for selective detection of LHBs. This antibody detects a subtype- and conformation-independent epitope of LHBs which is located at the surface of HBsAg particles (Heermann et al. 1984). The occurrence of MHBs was also studied using mAb Q19/10 which is specific for glycosylated preS2 antigen (Heermann et al. 1988).

The preS1 sequence 28-49 binds to human hepatoma cells (Neurath et al. 1986) and to isolated human hepatocyte membranes (Pontisso et al. 1989a). P. Pontisso et al. (1989b) found, moreover, that MA18/7 inhibits the binding of natural HBV to hepatocyte membranes. Thus, MA18/7 is an antibody against an attachment site of HBV. Human antibodies which inhibit the binding of MA18/7 to preS1 antigen would also most likely be anti-attachment antibodies. Such antibodies would be potentially protective. We searched for MA18/7-inhibiting antibodies in HBV carriers, in naturally immune persons and in recipients of two plasma-derived $H B$ vaccines.

\section{Materials and methods}

Serum samples and serological markers. Asymptomatic HBsAg carriers were ientified at various blood donation centers in Northern Germany and their rejected plasma was supplied to us. They were tested for hepatitis B e antigen ( $\mathrm{HBeAg}$ ), anti-HBe, anti-HBs, total anti-hepatitis B core antigen (anti-HBc) and IgM-anti$\mathrm{HBc}$ using enzyme immune assays which had been developed by our laboratory (Gerlich et al. 1986). The HBsAg concentration was assayed by electroimmunodiffusion (Gerlich and Thomssen 1975). They had low or absent IgM-anti-HBc titers and glutamate pyruvate transaminase levels of $<50 \mathrm{U} / 1$, and were anti-HBc positive.

Persons with recent or past HBV infection were identified in diagnostical samples which had been sent to our laboratory. Persons were considered to be recently infected if they were $\mathrm{HBsAg}$ negative and IgM-anti-HBc positive. Persons with past infections were total anti-HBc positive but IgM-anti-HBc negative.

Recipients of $\mathrm{HB}$ vaccines had been pretested for anti-HBc and anti-HBs. Only non-immune persons were vaccinated with three doses of $H B$ vaccine. Their anti-HBs response was quantitatively assayed 4 weeks after the third dose. Most 
recipients received a $\mathrm{HBsAg}$ vaccine (HB-Goe) which was purified from the plasma of non-viremic HBV carriers. This vaccine was not treated with proteases and contained small amounts of LHBs (Thomssen et al. 1982). Another group of vaccinees received a pepsin-treated $\mathrm{HBsAg}$ vaccine from the plasma of viremic carriers (H-B-Vax, MSD).

Detection of preS antigens. Forty-eight wells of a polystyrene microplate (Nunc B) were coated overnight with $100 \mathrm{ng}$ MA18/7 per well in $100 \mu$ of $0.0175 \mathrm{M}$ sodium phosphate buffer, $\mathrm{pH} 7.2$. The remaining wells were coated overnight with $100 \mathrm{ng}$ Q19/10 per well (same volume and same buffer as used for MA18/7). Postcoating was done with $1 \%$ (w/v) bovine serum albumin in $10 \mathrm{mM}$ Tris $\mathrm{HCl}, 0.13 \mathrm{M} \mathrm{NaCl}$, $1 \mathrm{mM}$ EDTA (TNE). Serum samples of $100 \mu \mathrm{l}$ were used undiluted. As positive control we used $5 \mu \mathrm{g} / \mathrm{ml} \mathrm{HBsAg}$ in TNE purified from serum of a viremic carrier (Stibbe and Gerlich 1982). As negative control we used pooled HBV marker negative human serum (NHS). PreS1 or preS2 antigen in the sample bound to the $\mathrm{mAbs}$, and bound HBsAg particles were recognized by anti-HBs covalently linked to horseradish peroxidase (Behringwerke, $100 \mu \mathrm{l} /$ well). All incubations were done for $1 \mathrm{~h}$ at $37^{\circ} \mathrm{C}$ with three washing steps in between using phosphate-buffered saline (PBS) $/ 0.05 \%$ TWEEN 20 . The enzyme linked to the solid phase was detected by 10 -min incubation at $25^{\circ} \mathrm{C}$ with orthophenylene-diamine dihydrochloride (OPD, $100 \mu \mathrm{l} /$ well) and hydrogen peroxide. $A_{492}$ was measured after addition of $100 \mu \mathrm{l} /$ well $1 \mathrm{M}$ sulfuric acid in a Dynatech Microplate Reader MR 600. All tests were done in triplicate. Results were always related to a strong positive control and expressed as percent absorbance of that control serum to eliminate the variation from plate to plate.

Detection of human anti-preS1 antibodies. Fifty microliters of undiluted serum and $250 \mathrm{ng}$ purified $\mathrm{HBs} \mathrm{Ag}$ in $50 \mu \mathrm{TNE}$ were mixed and preincubated for $1 \mathrm{~h}$ at $37^{\circ} \mathrm{C}$. PreS1 reactivity of the mixture was assayed as before. Sera which inhibited the binding of HBsAg to MA18/7 by less than $25 \%$ were considered negative for preS1 antibodies. Sera which inhibited the binding by $25 \%$ to $50 \%$ were considered borderline positive; sera were rated positive for preS1 antibodies when inhibiting more than $50 \%$. All tests were done in triplicates. Eight samples $(50 \mu 1)$ from different donors, who were negative for HBV markers, served as negative controls.

\section{Results}

\section{Specifity of MAl8/7}

The information on the epitopes of MA18/7 used for this study is summarized in Table 1. From this data it is apparent that several groups found the epitope of MA18/7 between amino acids 27 and 50 of the preS1 domain (numbering for subtype $\mathrm{adw}_{2}$ ). Moreover, two groups recently localized the epitope between amino acid 29 and 36. This epitope covers the amino-terminal part of the attachment site which has been identified by Neurath et al. (1986). The epitope contains at amino acid 35 an amino acid which is variable between different 
Table 1.

\begin{tabular}{ll} 
Reaction of MA18/7 with & Reference \\
\hline LHBs, not MHBs or SHBs & Heermann et al. (1984) \\
preS $(27-135)$ & Wong et al. (1985) \\
preS $(2-50)$ & H. Thoma pers. comm. \\
preS $(29-36)$ & P. Coursaget pers.comm. \\
preS (30-36) & S. Klimenko pers. comm. \\
LHBs liver attachment site & P. Pontisso et al. (1989a) \\
HBV liver attachment site & P. Pontisso et al. (1989b) \\
\hline
\end{tabular}

LHBs (MHBs, SHBs): Large (middle, small) HBs protein

HBV isolates. However, previous studies (Heermann et al. 1984) showed that all $\mathrm{HBV}$ subtypes available to us reacted equally well in the assay which was used for this study. Normal human sera do not react with the epitope of MA18/7.

\section{Specifity of $Q 19 / 10$}

MAb Q19/10 reacts in immune blots with MHBs but not with LHBs or SHBs. Deglycosylation of MHBs causes loss of reactivity. Thus, this antibody reacts with the preS2-glycopeptide of MHBs. No subtype-specific differences have been detected so far. Normal human sera contain a factor which inhibits binding of Q19/ 10 to HBsAg (Heermann et al. 1988). Thus, human antibodies to the epitope of Q19/10 or overlapping epitopes cannot be assayed by inhibition of Q19/10 without prior isolation of immune globulins from serum. Moreover, it is to be expected that small amounts of MHBs from HBsAg carriers may be masked by this serum factor (Heermann et al. 1988).

\section{Specifity of the preS ELISAS}

The preS-specifity of $\mathrm{HBsAg}$ binding to the mAb-coated microplates was controlled for a selected set of nine sera which contained between 1 and $67 \mu \mathrm{g}$ $\mathrm{HBsAg} / \mathrm{ml}$. All these sera produced signals between 0.86 and 1.87 absorbance units for the preS 1 antigen assay. There was no detectable correlation between the preS1 antigen signal and the total HBsAg concentration. The same sera produced signals between 0.000 and 0.096 absorbance units if coating of the microplates was done with nonspecific mouse IgG instead of mAb MA18/7. The nonspecific binding to the control microwells never exceeded $5 \%$ of the preS1-specific signal and was usually less than 0.010 absorbance units (Table 2). The preS2 signal was on the average weaker but it exceeded in seven cases the nonspecific signal. The two sera with less than $7 \mu \mathrm{g} \mathrm{HBsAg} / \mathrm{ml}$ were rated preS2 negative. 
Table 2. Specifity of the preS enzyme-linked immunosorbent assays (ELISAs). Nine different sera with various $\mathrm{HBs} \mathrm{Ag}$ concentrations and a negative human control serum (neg.) were tested for preS1 and preS2 antigen as described in the methods section. In parallel, the sera were tested in microplate wells which were coated with $10 \mu \mathrm{g} / \mathrm{ml} \mathrm{IgG}$ from mouse serum instead of monoclonal antibodies MA18/7 or Q19/10 (control). Tests were done in duplicate ( $a$ and $b$ )

\begin{tabular}{|c|c|c|c|c|c|c|}
\hline \multirow{2}{*}{$\begin{array}{l}\text { HBsAg } \\
\mu \mathrm{g} / \mathrm{ml}\end{array}$} & \multirow{2}{*}{$\begin{array}{l}\text { PreS1 } \\
\text { a }\end{array}$} & \multirow{2}{*}{$\underbrace{\text { ELISA }}_{\mathrm{b}}$} & \multirow{2}{*}{$\begin{array}{l}\text { PreS2 } \\
\mathrm{a}\end{array}$} & \multirow{2}{*}{$\begin{array}{l}\text { ELISA } \\
\text { b }\end{array}$} & \multicolumn{2}{|c|}{ Control } \\
\hline & & & & & $\mathrm{a}$ & $\mathrm{b}$ \\
\hline 66.8 & 1.862 & 1.885 & 0.815 & 0.656 & 0.074 & 0.096 \\
\hline 21.1 & 1.462 & 1.474 & 0.178 & 0.177 & 0.002 & 0.001 \\
\hline 15.1 & 1.337 & 1.348 & 0.109 & 0.140 & 0.001 & 0.001 \\
\hline 12.9 & 1.729 & 1.795 & 0.696 & 0.658 & 0.040 & 0.042 \\
\hline 12.0 & 1.663 & 1.619 & 0.132 & 0.164 & 0.004 & 0.005 \\
\hline 10.2 & 1.419 & 1.373 & 0.104 & 0.115 & 0.001 & 0.000 \\
\hline 7.9 & 1.610 & 1.626 & 0.105 & 0.106 & 0.002 & 0.003 \\
\hline 6.4 & 1.396 & 1.358 & 0.016 & 0.015 & 0.005 & 0.004 \\
\hline$<1.0$ & 0.811 & 0.905 & 0.046 & 0.043 & 0.000 & 0.000 \\
\hline neg. & 0.000 & 0.003 & 0.001 & 0.001 & 0.002 & 0.003 \\
\hline
\end{tabular}

\section{PreS antigen in HBsAg carriers}

Figure 1 shows the results of ELISAs for the preS1 and preS2 epitopes in relation to the HBsAg concentration in the tested sera. Results for preS are expressed as percent absorbance in comparison to a very strong positive reference sample. The $A_{492}$ of that positive sample was $1.860 \pm 0.101$ for preS1 antigen and $1.273 \pm 0.089$ for preS 2 antigen. Samples were considered positive for preS antigen when binding to the mAb was more than $10 \%$ of the positive HBsAg control. The $A_{492}$ of the negative controls was around 0.005 . Three groups were distinguished according to their $\mathrm{HBe}$ status.

Part A of Fig. 1 shows the data for $15 \mathrm{HBeAg}$-positive carriers. The majority of them (9) had high HBsAg concentrations of $>20 \mu \mathrm{g} / \mathrm{ml}$. All of them were MA18/7 and Q19/10 epitope positive. The assay for the Q19/10 epitope produced on the average weaker signals than the MA18/7 assay. The HBeAg carriers with lower HBsAg concentration $(<20 \mu \mathrm{g} / \mathrm{ml})$ were only partly $\mathrm{Q} 19 / 10$ positive $(3 / 6)$ or MA18/7 positive (5/6).

Part B shows the data for $11 \mathrm{HBsAg}$ carriers without HBe markers. Their HBsAg concentration did not exceed $20 \mu \mathrm{g} / \mathrm{ml}$. All sera were preS1 epitope positive but their reactivity was weaker than in the group in A. PreS2 epitope was clearly detectable in five carriers only and borderline positive in two.

Anti-HBe-positive carriers (part C) had always HBsAg concentrations of $<20 \mu \mathrm{g} / \mathrm{ml}$. The great majority was preS1 epitope positive (44/46). The two preS1 epitope-negative samples had $<0.5 \mu \mathrm{g} \mathrm{HBsAg} / \mathrm{ml}$. Again the preS2 epitope was less frequently detectable (12/46). All preS2 epitope-positive sera had $<5 \mu \mathrm{g}$ $\mathrm{HBsAg} / \mathrm{ml}$. 

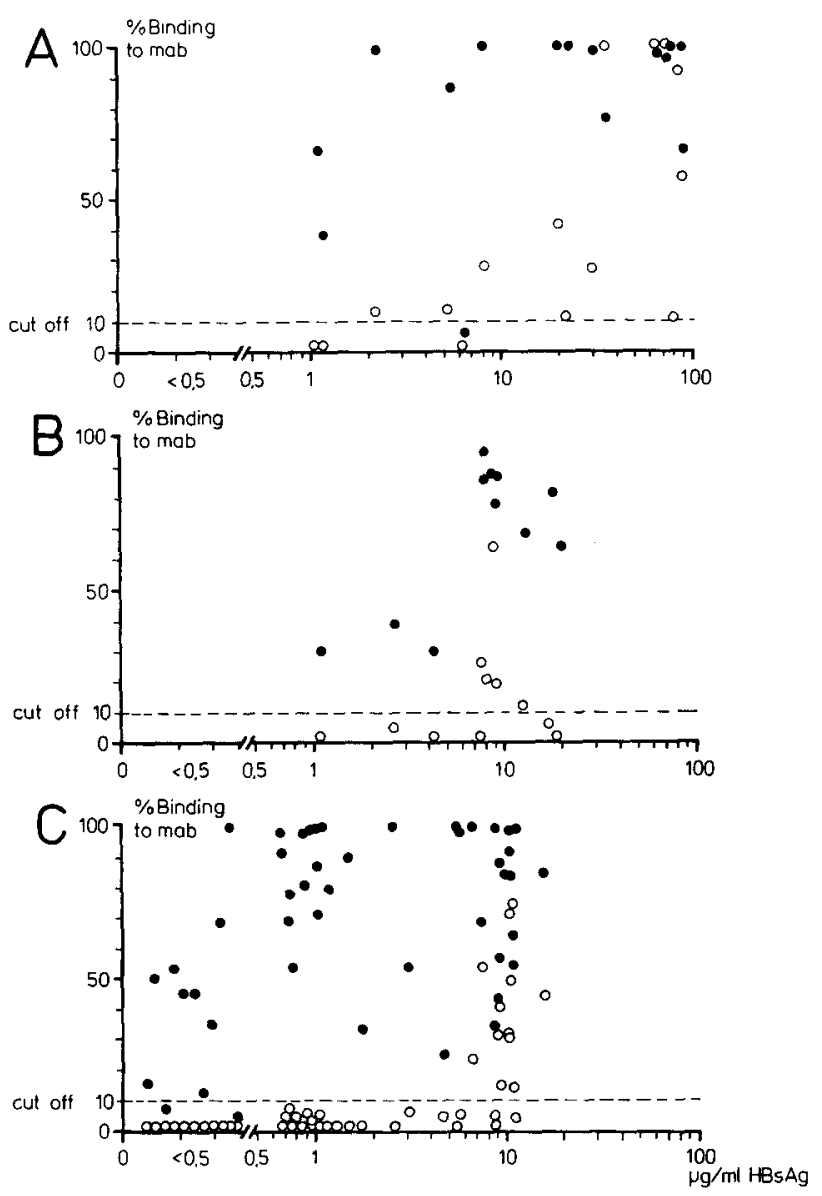

Fig. 1A-C Relationship between preS1 (O) or preS2 (O) antigen and total hepatitis $B$ surface antigen ( $\mathrm{HBsAg}$ ) concentration in asymptomatic HBsAg carriers. A HBeAgpositive carriers; $\mathrm{B}$ HBeAgand anti-HBe-negative carriers; $\mathbf{C}$ anti-HBe-positive, $\mathrm{HBeAg-negative} \mathrm{carriers}$

The data suggest that the binding capacity of the MA18/7-coated microwells is often saturated at concentrations of $0.5 \mu \mathrm{g} \mathrm{HBsAg} / \mathrm{ml}$. Since most HBsAg carriers have higher concentrations than $0.5 \mu \mathrm{g} \mathrm{HBsAg} / \mathrm{ml}$ no quantitative correlation between the preS1 assay and the total HBsAg concentration could be expected. However, the majority of the samples $(47 / 59)$ with more than $0.5 \mu \mathrm{g} / \mathrm{ml} \mathrm{HBsAg}$ produced submaximal signals in the preS 1 assay. This suggests that the proportion of reactive preS1 epitopes to total $\mathrm{HBsAg}$ is variable betweeen different $\mathrm{HBsAg}$ carriers. With the preS2 assay, saturation of the assay was only reached in three cases (Part A of Fig. 1).

\section{Anti-preS1 antibodies in naturally infected persons}

Sera from various groups of persons were tested to see if they could compete with $\mathrm{mAb}$ MA18/7 for its epitope or overlapping epitopes in the preS1 domain (see Table 3) using the inhibition assay as described in the methods section. The mean 
Table 3. Detection of MA18/7 inhibiting anti-preS1 antibodies in various states of (HBV) infection and in HBV vaccine recipients. Sera which inhibited the binding of HBsAg/MA18/7 less than 25\% were considered negative for preSl antibodies. Sera were considered weakly positive when inhibiting this binding by $25 \%$ to $50 \%$; sera were positive for preSI antibodies when inhibiting mor than $50 \%$

\begin{tabular}{|c|c|c|c|c|}
\hline \multirow[t]{2}{*}{ Serological state } & \multicolumn{4}{|c|}{ Number of persons } \\
\hline & Negative & $\begin{array}{l}\text { Weakly } \\
\text { Positive }\end{array}$ & Positive & Total \\
\hline \multicolumn{5}{|l|}{ HBsAg carriers } \\
\hline $1^{\mathrm{a}} \mathrm{HBeAg}+$ & 9 & 0 & 0 & 9 \\
\hline $2 \mathrm{HBeAg} \varnothing$ & 33 & 12 & 4 & 49 \\
\hline \multicolumn{5}{|l|}{ Previous HBV infect. ${ }^{b}$} \\
\hline IgM-anti-HBc $\varnothing$ & & & & \\
\hline 3 anti-HBs + & 29 & 15 & 14 & 58 \\
\hline 4 anti-HBs $\varnothing$ & 51 & 10 & 3 & 64 \\
\hline $5 \quad$ IgM-anti-HBc + & 22 & 6 & 4 & 32 \\
\hline \multicolumn{5}{|l|}{ Vaccine recipients $^{c}$} \\
\hline 6 HB-Goe & 15 & 5 & 24 & 44 \\
\hline 7 H-B-Vax & 11 & 0 & 6 & 17 \\
\hline 8 Controls $^{\mathrm{d}}$ & 60 & 0 & 0 & 60 \\
\hline
\end{tabular}

a Group number used in the text

b HBsAg $\varnothing$, anti-HBc +

c Four weeks after third dose

d HBsAg $\varnothing$, anti-HBc $\varnothing$, anti-HBs $\varnothing$

value of the negative controls was between 1.419 and 1.508 on different plates. The variation coefficient was $3 \%$ within one plate, and $6.12 \%$ between different plates.

Sera without HBV markers (group 8 of Table 3 ) did not show any significant inhibition. The same was true for nine $\mathrm{HBeAg}$-positive $\mathrm{HBs} \mathrm{Ag}$ carriers (group 1 of Table 3). However, $33 \%$ of the HBeAg-negative HBsAg carriers inhibited the binding of preS1 antigen to mAb MA18/7 (group 2 of Table 3), most of them weakly.

A significant inhibiting activity was also found among 154 persons (total number) with a previous HBV infection (group 3-5 of Table 3). MA 18/7 inhibiting antibodies were found in $50 \%(29 / 58)$ of those persons who were anti-HBc, antiHBs positive (group 3 of Table 3 ). There was no correlation between anti-preS1 and anti-HBs titer in these naturally immune persons (Fig. 2A). Their titer of antiHBs did not exceed $10^{4}$ I.U./l (median value 90). In group 4 (HBsAg negative, IgManti-HBc negative, anti-HBs negative, but anti-HBc positive) $20 \%$ of the cases (13/ 64) were found positive for anti-preS1 antibodies. Convalescents of a recent HBV infection who were $\mathrm{HBsAg}$ negative, anti-HBs negative but IgM-anti-HBc positive (group 5 of Table 3 ) had a similar proportion of anti-preS1 antibody $(31 \% ; 10 / 32$ ) as the naturally immune group. 

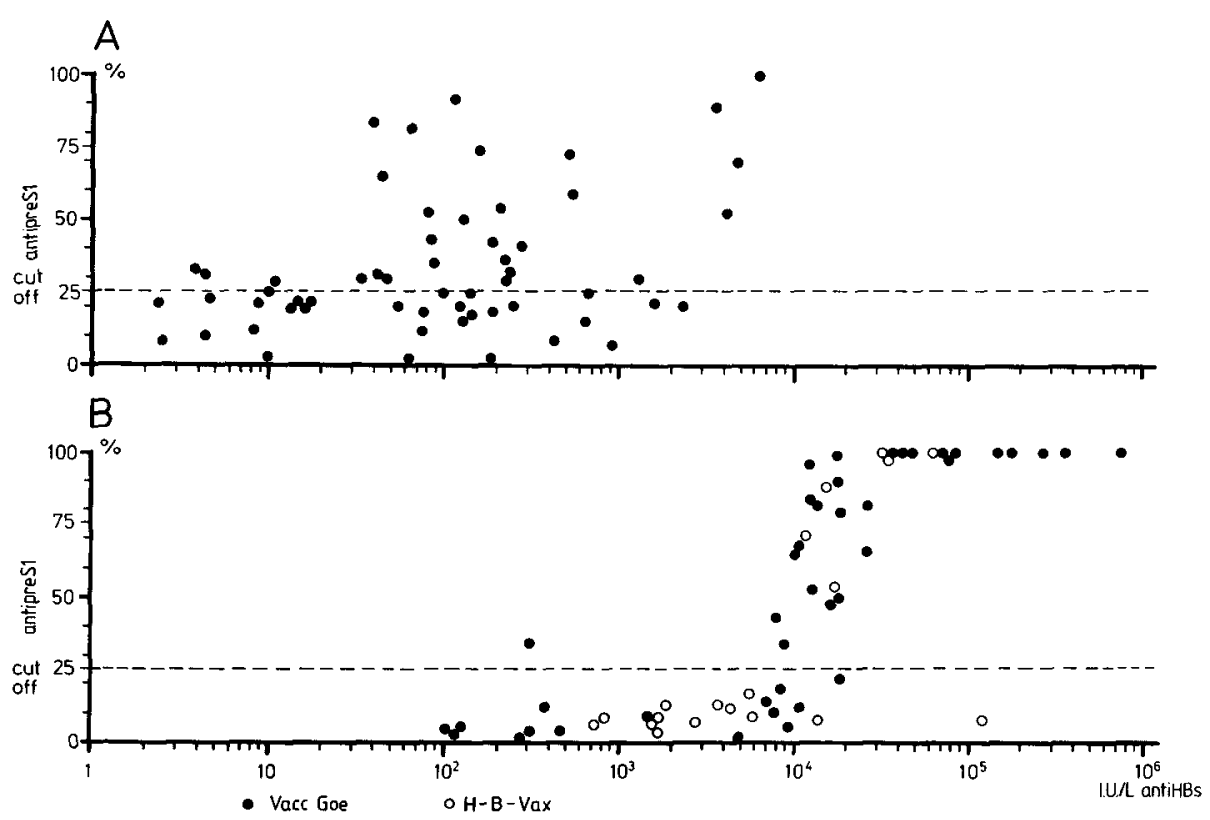

Fig. 2A-B Relationship between MA18/7 inhibiting anti-preS1 reactivity and anti-HBs titers in naturally immune persons (A) or recipients of plasma-derived vaccines (B). HB-Goe (O), H-B-Vax (O)

\section{Anti-preS1 in vaccinees}

Two different hepatitis B vaccines were compared. Vaccine HB-Goe was expected to induce some anti-preS 1 because previous analysis had shown that it contained small amounts of LHBs (Thomssen et al. 1982). The majority $(66 \% ; 29 / 44)$ of the anti-HBs-positive recipients indeed also showed anti-preS1 (group 6 of Table 3). The second vaccine H-B-Vax was expected to be free of preS1 antigen, because it was treated with pepsin during its preparation. It is known that pepsin causes cleavage of preS antigens (Hu and Peterson 1988). However, several of these vaccine recipients $(6 / 17)$ also showed a clear anti-preS1 response (group 7 of Table 3).

It was of interest to ask if the anti-preS1 response was correlated to the antiHBs response. This was indeed the case (Fig. 2B). Significant anti-preS1 reactivity was only observed if the anti-HBs titer was $>10^{4}$. U/liter. This was true for both vaccines.

\section{Discussion}

This study confirms the findings of Hu et al. (1987) and of Budkowska et al. (1988) that LHBs or preS1 antigen is not a diagnostical marker of massive viremia in chronic arriers. Although we have previously reported that virions and HBs 
filaments contain more LHBs than 20-nm particles it became now clear that 20-nm particles from virtually all HBs Ag carriers contain LHBs in variable concentrations. Even in carrier blood with $2 \times 10^{8}$ virions, the major amount of LHBs is localized on 20-nm particles (Lenz 1987). There may be a quantitative correlation of LHBs to the total amount of HBs but we did not attempt to determine quantitatively the MA18/7 epitopes beyond saturation of the assay. The low values of the preS1 ELISA in some carriers with high HBsAg concentrations suggests that either they contain atypically low levels of LHBs or that the LHBs is masked by antibody. The detection of anti-preS1 in some of these carriers supports the second explanation. The detection of an attachment-related epitope in most HBsAg carriers suggests that hepatocyte membranes of these carriers are saturated by or unreactive for the preS1 attachment site.

The assay of the preS1 epitope by mAb MA18/7 may be a useful marker for resolving acute hepatitis $\mathrm{B}$, because this preS1 epitope disappears much more rapidly than total HBsAg from the blood of the patients (Gerken et al. 1987). However, other parameters like $\mathrm{HBeAg}$, total $\mathrm{HBsAg}$ concentration or HBVDNA are at least as good parameters of resolution.

In agreement with many previous studies on the polyalbumin receptor, the preS2 epitope showed a certain correlation to $\mathrm{HBeAg}$ and, thus, implicitely massive viremia. The relationship may be only indirect. The preS2 epitope that reacts with Q19/10 was undetectable in most samples containing $<8 \mu \mathrm{g} \mathrm{HBsAg} / \mathrm{ml}$. The observation that $\mathrm{HBeAg}$-positive $\mathrm{HBV}$ carriers have higher concentrations than anti-HBe-positive carriers (Thomssen et al. 1983) is confirmed by our study. However, $\mathrm{HBe} A g$ and anti-HBe are more reliable markers of viremia than freepreS2 epitopes or total HBsAg concentration. Previous studies of our group had shown that NHS contains a preS2 binding factor. The amount of this factor is, however, so low that only MHBs of 5-10 $\mu \mathrm{g} \mathrm{HBs} \mathrm{Ag} \mathrm{can} \mathrm{be} \mathrm{saturated} \mathrm{by} 1 \mathrm{ml}$ serum (Heermann et al. 1988). This factor is possibly monomeric human serum albumin (B. Krone et al., in press) which is somehow modified by an unknown cofactor. The results of this study extend our previous observations. It appears possible that $\mathrm{mAbs}$ against other epitopes of preS2 antigen may not be blocked by the naturally occurring serum factor. To examine whether the samples which were negative for the preS2 epitope in the ELISA really contain no MHBs, part of these samples were tested by immunblot with Q19/10. Using this technique we were in fact able to detect MHBs in these sera (Heermann et al. 1988). However, we do not believe that assay of MHBs by such methods is diagnostically useful, because virtually all sera would be positive. In contrast, qualitative assays of free preS2 sequences using $Q 19 / 10$ may be a substitute for quantitative determination of total $\mathrm{HBsAg}$ concentration.

Anti-preS1 has been found very early in acute hepatitis B infection by Westernblot (Theilmann et al. 1986), by radioimmunprecipitation of HBV particles (Alberti et al. 1978) or by ELISA (Alberti, pers. communication). The relatively infrequent appearance of MA18/7 inhibiting anti-preS1 in our study suggests that other epitopes of preS1 may be more active in induction of antibodies. In agreement with this conclusion, sequences 12-32 of preS1 have been found as major B cell immunogens of preS1 (Neurath et al. 1986; Milich et al. 1986). However, an ELISA using the whole preS1 sequence in a fusion protein (Deepen et al., in preparation) did not generate more positive results in naturally 
immune or HBV-infected persons. Thus, we conclude that the MA18/7 inhibition assay is representative for the humoral immune response against the sequential preS1 epitopes. The appearance of anti-preS1 in anti-HBs-negative persons with previous HBV infection shows that the current assays for anti-HBs do not detect all antibodies against the viral surface.

The protective role of antibodies against epitopes in sequence 12-32 is not known. Although a protective function of MA18/7 or of cross-reactive antibodies has also not been experimentally proven, inhibition of hepatocyte attachment by MA 18/7 suggests that such antibodies may be virus neutralizing (Pontisso et al. 1989 b). In agreement with this assumption, Neurath et al. (1988) have shown that the preS1-peptide (21-47) antisera neutralize infectivity of $\mathrm{HBV}$ in chimpanzees.

Our data do not suggest that the epitope of MA18/7 and overlapping epitopes would help to induce antibodies in vaccinees who do not respond to SHBs. Antibodies to these epitopes were observed only in vaccinees who had very high titers of anti-SHBs. It has to be considered, however, that the vaccines used here contained very small amounts of preSl antigen. It was actually a surprise to find any anti-preS1 response in the recipients of $\mathrm{H}-\mathrm{B}-\mathrm{Vax}$. Our data suggest that pepsin cleavage of preS1 in this vaccine was incomplete, or that the epitope of MA18/7 remained in the vaccine inspite of proteolysis. One might suspect that the inhibition of MA18/7 binding in these vaccine recipients sera could be due to sterical hindrance by large amounts of anti-SHBs instead of anti-preS1. However, the direct ELISA for anti-preS1 using a preS1-fusion protein (Deepen et al., in preparation) also generated very similar results in this group.

An increase in the proportion of LHBs or preS1 antigen in HB vaccines would probably increase the anti-preS1 response. This was noted previously in mice and guinea pigs (Heermann et al. 1987). Ferrari et al. (1989) showed that recipients of a HBV vaccine which contained only very small amounts of LHBs (Hevac B, Pasteur) developed, nevertheless, predominantly preS1-specific $\mathrm{T}$ helper cell clones. In naturally immune persons the anti-SHBs response is on the average weaker than in vaccinees but the anti-preS1 response is as good or better. Moreover, in agreement with the studies of Alberti et al. (1987), Theilmann et al. (1987) or Takai et al. (1986) anti-preS1 was detectable in the absence of anti-HBs, or even in the presence of HBsAg. The detection of anti-preS1 in many anti-HBepositive $\mathrm{HBs} \mathrm{Ag}$ carriers suggests that this antibody may be involved in the selective removal of HBV particles. The absence of severe liver diseases in these carriers shows, furthermore, that an anti-preS1 response is not linked to pathogenesis.

In summary our study does not characterize the preS antigens as important diagnostical markers. It appears, however, advisable to include a reactivity for anti-preS1 in the current assays for anti-HBs. This is of special importance for further vaccine development. Detection of anti-preS2 either separately or together with anti-HBs and anti-preS1 would be also desirable, but the interference of serum factors has to be carefully evaluated.

Acknowledgements. We thank Drs. H. Thoma (Munich), P. Coursaget (Tours) and S. Klimenko (Moscow) for communicating their findings on the binding of MA18/7 to preS1 peptides. We also thank U. Goldmann and R. Hobein for technical assistence. The work was partially supported by DFG grant GE 345/7-3. 


\section{References}

Alberti A, Diana S, Scullard GH, Eddlestone ALWF, Williams R (1978) Detection of a new antibody system reacting with Dane particles in hepatitis B virus infections. Br Med J 2:1056-1058

Alberti A, Pontisso P, Fraiese A, Milanesi G, Stenico D, Gianni M, Chemello C, Realdi G (1987) The preS/anti-preS systems in hepatitis B virus infection . In: Robinson WS, Koike K, Will H (eds) Hepadna viruses. Alan R. Liss, New York, pp 147-160

Budkowska A, Dubreuil P, Gerlich WH, Lazizi Y, Pillot J (1988) Occurrence of preS1 antigen in viremic and nonviremic carriers of hepatitis B surface antigen. J Med Virol 26:217-225

Ferrari C, Penna A, Bertoletti A, Cavalli A, Valli A, Schianchi C, Fiaccadori F (1989) The preS1 antigen of hepatitis B virus is highly immunogenic at the $T$ cell level in man. $J$. Clin Invest 84:1314-1319

Gerken G, Manns M, Gerlich WH, Hess G, Meyer zum Büschenfelde K-H (1987) PreS encoded surface proteins in relation to the major surface antigen in acute hepatitis $B$ virus infections. Gastroenterology 92:1864-1868

Gerlich WH, Thomssen R (1975) Standardized detection of hepatitis B surface antigen: determination of its serum concentration in weight units per volume. Dev Biol Stand 30:78-87

Gerlich WH, Uy A, Lambrecht F, Thomssen R (1986) Cutoff levels of immunoglobulin M antibody against viral core antigen for differentiation of acute, chronic and past hepatitis $B$ virus infections. $J$ Clin Microbiol 24:288-293

Heermann K-H, Goldmann U, Schwartz W, Seyffarth T, Baumgarten H, Gerlich WH (1984) Large surface proteins of hepatitis B virus containing the pre-S sequence. J Virol 52:396-402

Heermann K-H, Kruse F, Seifer M, Gerlich WH (1987) Immunogenicity of the gene S and the pre-S domains in hepatitis B virions and HBsAg filaments. Intervirology 28:14-25

Heermann K-H, Waldeck F, Gerlich WH(1988) Interaction between native human serum and the preS2 domain of hepatitis B virus surface antigen. In: Zuckerman AJ (ed) Viral hepatitis and liver disease. Alan R. Liss, New York, pp 697-700

Hu P-S, Peterson DL (1988) Use of monoclonal and antipeptide antibodies to study the structure and arrangment of the pre-S proteins of hepatitis B surface antigen. In: Zuckerman AJ (ed) Viral hepatitis and liver disease. Alan R. Liss, New York, pp 318-322

Hu P-S, Carithers RL, Fiorenza V, Peterson DL (1987) Quantitative studies of the hepatitis B viral pre-S proteins: lack of correlation with the HBeAg status. J Virol Methods 16:97-114

Lenz A (1987) Bindung von nativem Humanalbumin an die PräS2 Domäne des Hepatitis B Virus. MD Thesis, University of Göttingen

Milich DR, McLachlan A, Chisari FV, Kent SBH, Thornton GB (1986) Immune response to the pre$\mathrm{S}(1)$ region of the hepatitis $\mathrm{B}$ surface antigen (HBsAg): a pre-S(1) specific $\mathrm{T}$ cell response can bypass nonresponsiveness to the pre-S(2) and S regions of HBsAg. J Immunol 137:315-322

Neurath AR, Kent SBH, Strick N, Parker N (1986) Identification and chemical synthesis of a host cell receptor binding site on hepatitis $B$ virus. Cell 46:429-436

Neurath AR, Strick N, Kent SBH, Parker K, Seto B, Girard M (1988) Design of synthetic peptides mimicking the immunologic and biologic functions of the preSl sequence of the hepatitis $\mathrm{B}$ virus envelope protein. In: Ginsberg H, Brown F, Lerner RA, Chanock RM (eds) New chemical and genetic approaches to vaccination. Cold Spring Harbor Laboratory, New York, pp 229-234

Pontisso P, Petit MA, Bankowski MJ, Peeples ME (1989a) Human liver plasma membranes contain receptors for the hepatitis B virus pre-S1 region and, via polymerized human serum albumin, for the pre-S2 region. J Virol 63:1981-1988

Pontisso P, Ruvoletto MG, Gerlich WH, Heermann K-H, Bardini R, Alberti A (1989b) Identification of an attachment site for human liver plasma membranes on hepatitis B virus particles. Virology 173:522-530

Stibbe W, Gerlich WH (1982) Variable protein composition of hepatitis B surface antigen from different donors. Virology 123:436-442

Takai E, Machida A, Ohnuma H, Miyamoto H, Tanaka T, Baba K, Tsuda F, Usuda S, Nakamura T, Miyakawa Y, Mayumi M (1986) A solid-phase enzyme immunoassay for the determination of IgM and IgG antibodies against translation products of pre-S1 and pre-S2 regions of the hepatitis B virus. J Immunol Methods 95:23-30 
Theilmann L, Klinkert MQ, Gmelin K, Salfeld J, Schaller H, Pfaff E (1986) Detection of preS1 proteins in serum and liver of $\mathrm{HBeAg-positive} \mathrm{patients:} \mathrm{a} \mathrm{new} \mathrm{marker} \mathrm{for} \mathrm{hepatitis} \mathrm{B}$ virus infection. Hepatology 6:186-190

Theilmann L, Klinkert MQ, Gmelin K, Kommerell B, Pfaff E (1987) Detection of antibodies against pre-S1 proteins in sera of patients with hepatitits B virus (HBV) infection. J Hepatol 4:22-28

Thomssen R, Gerlich WH, Böttcher U, Stibbe W, Legler K, Weinmann E, Klinge O, Pfeiffer U (1982) Herstellung und Erprobung eines Hepatitis-B-Impfstoffes. Dtsch Med Wochenschr 4:125-131

Thomssen R, Gerlich WH, Böttcher U, Legler K, Stibbe W, Ritter S, Weinmann E, Klinge O, Pfeiffer U (1983) Safety and potency aspects in the preparation of an experimental HBsAg vaccine. Dev Biol Stand 54:23-31

Wong DT, Nath N, Sninsky JI (1985) Identification of hepatitis B virus polypeptides encoded by the entire of pre-S open reading frame. J Virol 55:223-231

Received October 25, 1989 